\title{
Research of Automatically Light-Adjusting Lamp
}

\author{
Biqing $\mathrm{Li}^{1, \text { a }}$, Aizhen Zhou, a, *, Chongjun Yang ${ }^{1, \text { a }, \text { Shiyong Zheng }}$ 3, b \\ ${ }^{1}$ College of Mechanical and Electronic Engineering, Hezhou University, Hezhou Guangxi 542899, \\ China; \\ ${ }^{2}$ Liuzhou Jiacheng automotive trim Systems Co. Ltd, Liuzhou Guangxi 545000, China; \\ ${ }^{3}$ College of Computer Science and Information Engineering, Hezhou University, Hezhou Guangxi \\ 542899, China. \\ ajanliful@163.com, b229292710@qq.com
}

\begin{abstract}
This design adopting 80C51 microcontroller and a few external circuit to control lights, using silicon controlled dimming technology, by means of single chip control bidirectional thyristor turn-on to achieve incandescent lamps (resistive load) brightness adjustment, thus achieving the photometric light and dark control and regulation of the effect of fluorescent lamp, realizing fluorescent lamp dimming control, so that the fluorescent lamp according to the external light dark level generated by the effect of light and shade, which can also through manual debugging to adjust the fluorescent lamp brightness, and realize intelligent control. With low cost, simple and easy to work, the design has excellent controllability and practicability.
\end{abstract}

Keywords: Single-chip microcomputer; controllable silicon; light-adjusting lamp.

\section{Introduction}

In daily life, we often need to adjust the brightness of the lighting or the production of lighting. The dimming control circuit is designed to realize the adjustment of the brightness of the incandescent lamp (pure resistance load) by the single-chip microcomputer controlled bidirectional thyristor [1].

The realization mode of the light modulation is that after a period of zero crossing of the AC power supply signal, a bidirectional thyristor can be triggered. The smaller the trigger angle, the shorter the lead time, the longer the time of thyristor conduction, the brighter the brightness of the lamp; on the contrary, the lamp will become more and darker. This is required to determine the AC power synchronization signal zero crossing, and based on this, to control the trigger angle of the trigger angle of the size, to achieve the purpose of incandescent brightness adjustment[2].

\section{Circuit design}

The block diagram of the dimming controller is as follows:

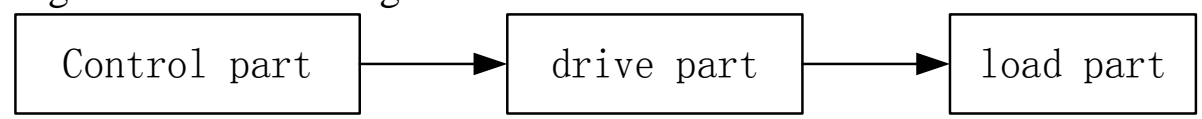

Fig. 1 dimming controller block diagram

Main control circuit with AT89C51 microcontroller as the main components, the control circuit is shown as Fig. 1. When the AC voltage pass zero o'clock signal, the synchronization signal SYN generated during the using would connected to the INT0 of microcontroller, the decline of this signal will cause a certain time of interruption of the microcontroller, as a starting point for the delay signal. In the circuit, the non-contact switch element is adopted to control the bidirectional thyristor. The bidirectional thyristor can control the conduction of the AC power supply without contact, small current controlling the large current, and with fast action, long use life, and high reliability [3].

Single chip computer will start a delay program after receiving the synchronization signal, the specific delay time changed by the button. After the end of the delay, the microcontroller immediately produce a trigger signal. The trigger signal can make the controlled silicon in the conduction state, and the current passing by the silicon and then make incandescent lamp glow. The longer the delay time, the shorter the time of the incandescent lamp, and the brightness of the lamp is darker. It's 
because that the length of delay time is determined by length of the button time, in fact the key control the brightness of the light. The general flow chart of the system program is shown in the following Fig. 2 .

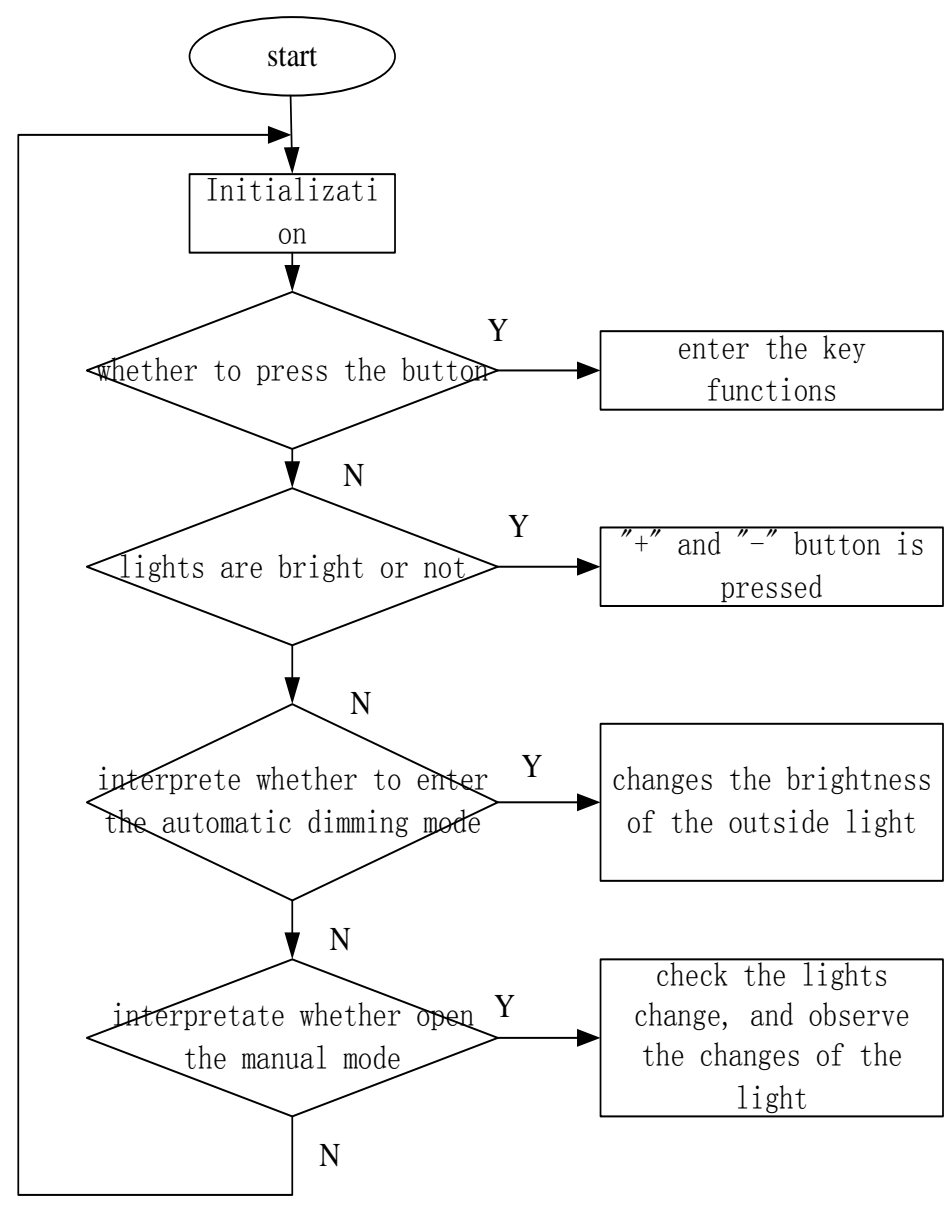

Fig. 2 total flow chart

In this design, the main program is mainly under the control of single-chip microcomputer, storing and analyzing the information input keyboard. Drive the external circuit[4], and through comparative analysis of the external light intensity controlling the two-way controllable silicon channel, so as to control the current and indicate the brightness change of the incandescent lamp. In this process, the single-chip microcomputer first need to be initialization, including setting the direction of each I-O microcontroller, the initialization of each variable and the calibration of the frequency of single chip oscillation[5], etc. The main program flow chart is shown in Fig. 3.

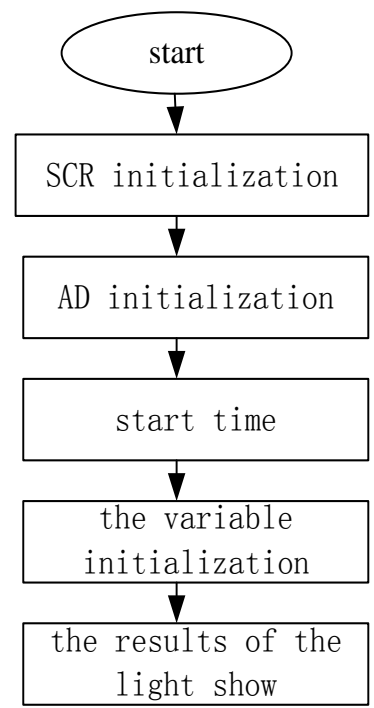

Fig. 3 Main control program flow 


\section{Conclusion}

The system uses 51 single chip computer AT89S51 programming to control the bidirectional thyristor conduction to realize the adjustment of the brightness of the incandescent lamp (pure resistance load), and realize the automatic and manual switch, with better practicability. The design of the automatically light-adjusting lamp has higher degree of automation, suitable for daily family and public life, such as: corridor lights, street lamps and so on, which has a high practical value. Automatic and manual control of the system are complete, which can make the brightness of the lamp change more easily according to the use of personal habits, can make the application of automatic dimming lights more widely, has a certain application prospects.

\section{Acknowledgements}

This work is supported the following fund:

2016 The project of improving the basic ability of young teachers in Colleges and universities in Guangxi: "Design and development of electronic commerce platform of agricultural products based on Semantic Technology" (No, KY2016YB455).

2016 Guangxi higher education teaching reform project: "Exploration on the cultivation mechanism of the teaching characteristics of Communication Engineering Specialty Based on ZTE ICT education platform"

2015 college students' innovative training program: "Research on the application of value added travel experience in the mobile terminal of the "ethnic custom travel' in Guangxi" (No 201511838070); \&\& "The design and development HeYuanTong Campus Mobile Phone APP based on Android" (No 201511838034).

2015 Teaching case project construction project of hezhou university: "Tourist positioning and guiding system project of Huangyao scenic"; \&\& "Development and application of the information management system of "Huang Yao Tong"'.

Project of scientific research and technology development project of Hezhou: "Design and implementation of agricultural products e-commerce platform based on Semantic Technology" (No, Hekeneng 1506006)

Scientific research project of hezhou university: "Research and development of E-government platform based on mobile terminal" (No 2015ZZZK03);

Reform in Education project of hezhou university: "Internet of things" (No hzxytszy201501); "Research on application personnel training model of Communications for SMEs" (No hzxyjg201525);

Master degree discipline construction scientific research and Cultivation Project: "Research on the social work service of the teenagers' Network Addiction" (No 2015SHGZ005) \& \& "Research on the intelligent development of rural tourism in Guangxi based on the Internet of things" (No 2015MTA16).

\section{References}

[1]. .Zheng SQ, DZ; Qiang, Z; Li, BQ. Design and Implementation of Supermarket Personnel Management System Based On Java. In: Chen PZ, S, editor. 2nd International Conference on Education, Management and Computing Technology (ICEMCT); Tianjin, PEOPLES R CHINA: ATLANTIS PRESS; 2015. p. 1724-7.

[2]. .Li BG, WL; Zheng, SY; Yue, XG. OPTIMISATION DESIGN OF CORN PRECISION SEEDER BASED ON MULTI-ROUTE AND MULTI-CHANNEL CONTROL [J]. JOURNAL OF THE BALKAN TRIBOLOGICAL ASSOCIATION. 2015, 21(4A): 1215-23.

[3]. .Zheng SG, Weili; Li, Biqing. Social Work in Teen Addiction Correction Services Research under the New Situation. In: Wang JX, P, editor. 4th National Conference on Electrical, 
Electronics and Computer Engineering (NCEECE); Xian, PEOPLES R CHINA: ATLANTIS PRESS; 2016. p. 252-5.

[4]. .Zheng SG, WL; Li, BQ. Digital Display Design of Ethnic Clothing of Nanling. In: Liang ZL, X, editor. 4th International Conference on Mechatronics, Materials, Chemistry and Computer Engineering (ICMMCCE); Xian, PEOPLES R CHINA: ATLANTIS PRESS; 2015. p. 2805-8.

[5]. .Shiyong Zheng WG, Jing Wang, Biqing Li, Deze QIN. Analysis of Internet of Things Talent Training and Curriculum System Innovation. 3th International Conference on Education, Management and Computiong Technology; HangZhou, China: ATLANTIS PRESS; 2016. p. 957-60. 